\title{
"En medio del enclaustro, lugar tan acabado, / sediá un rico árbol en medio levantado": contextos y funciones ecfrásticas del árbol autómata en el Libro de Alexandre
}

\section{"En medio del enclaustro, lugar tan acabado, / sediá un rico árbol en medio levantado": ekphrastic context and functions on the automat tree in the Libro de Alexandre}

\author{
Gerardo Altamirano \\ Universidad Nacional Autónoma de México \\ altamiranogr@gmail.com
}

\begin{abstract}
Uno de los pasajes más interesantes en el Libro de Alexandre, texto que reactualiza para su época la vida de Alejandro magno y añade aspectos de literatura fantástica, es, sin duda, el hallazgo del protagonista, Alejandro Magno, con el Palacio del rey Poro. En este episodio, el rey macedonio encuentra un árbol construido en oro que constituye, al parecer, un autómata, es decir una especie de robot o ente que se mueve por ciertas energías físicas. En este artículo, el autor trata de ahondar en este pasaje, revelando sus funciones intra y extratextuales, así como su relación intertextual y extratextual con otras obras y episodios o aspectos históricos.
\end{abstract}

Palabras Clave: Libro de Alexandre, autómatas, árbol áureo, Poro, Alejandro Magno

One of the most interesting passages in El Libro de Alexandre, a text that updates for the Middle Ages the life of Alexander the Great and adds certain fantastic aspects, is, with no doubt, the finding of Poro's Palace, located in India. In this episode, the Macedonian king finds a tree made of gold that is an automat, it means a kind of robot that moves itself by certain physical forces. In this paper, the author tries to get deeper in this passage and reveals its intra and extratextual functions, as well as its intertextual and extratextual relationship, concerning other literary works and historical aspects.

KEYworDs: Libro de Alexandre, automat, golden tree, Porus, Alexander the Great

FECHA DE RECEPCIÓN: 30/11/2016

FECHA DE ACEPTACIÓN: 7/03/2017 
$\mathrm{E}$ ntre los pasajes que potencialmente integran un catálogo de rarezas y maravillas en el Libro de Alexandre, un lugar especial lo ocupa el del árbol autómata que se encuentra en medio del palacio del monarca indio, Poro (cc. 2131-2142). ${ }^{1}$ Con respecto a este episodio, la crítica ha develado algunos aspectos que hoy resultan valiosos. Este es el caso del estudio de Ian Michel ("Automata in the Alexandre"), quien acertadamente contextualiza históricamente el motivo y da a conocer, en términos de Genette (Palimpsestes, 20), la trayectoria transtextual que posee el árbol áureo del LA con respecto a otras obras precedentes. En este sentido, Michel hace evidente que si bien el autómata no se encuentra en el hipotexto griego más arcaico de la obra - es decir el texto del Pseudo Calístenes, Vida y hazañas de Alejandro de Macedonia-, sí se halla, por el contrario, y de modo constante, en las traducciones y adaptaciones latino-medievales que se hicieron de la afamada novela griega. Una tradición que, hacia el siglo $\mathrm{x}$, inauguró la célebre Historia de Proeliis.

No obstante, y debido a sus características retóricas, este pasaje puede leerse también como una écfrasis, si por este concepto entendemos tanto lo señalado por los rétores antiguos, como también lo especificado por la teoría moderna. ${ }^{2}$ De este modo, habría que recordar que, a mediados del siglo pasado, Spitzer definió la écfrasis como: "the poetic description of a pictorial or sculptural work of art" (“The ode on a Grecian Urn”, 226). En otras palabras, si bien antiguamente el concepto abarcaba cualquier tipo de descripción, en la actualidad éste remite a un retrato literario de una supuesta obra plástica que, a menudo, sólo existe única y exclusivamente por el poder del lenguaje. En este trabajo, demostraré que el concepto puede ser aplicado a la descripción del árbol autómata en el $L A$ y, asimismo, me centraré en las funciones y contextos intra y extratextuales que el pasaje conlleva. Empero, antes de analizar el episodio, es necesario un breve recuento conceptual y literario acerca del objeto de estudio.

\footnotetext{
${ }^{1}$ Desde aquí, cito las cuadernas correspondientes del Libro de Alexandre, según la edición de Juan Casas Rigall. Asimismo, para abreviar el título de la obra utilizaré las siglas LA; mientras que cuando me refiera a la Historia de Proeliis utilizaré, si para la economía del texto es conveniente, la abreviación $H P$.

${ }^{2}$ Los rétores antiguos entendían por écfrasis cualquier tipo de descripción, no solamente de objetos artísticos. En este sentido, hacia el siglo IV, Aftonio de Antioquía señalaba que: "una descripción (écfrasis) es una composición que expone en detalle y presenta ante los ojos de manera manifiesta el objeto descrito. Se han de describir personajes y hechos, circunstancias y lugares, animales y, además, árboles y personajes, como lo hace Homero" (Ejercicios, 253-254).
} 


\section{LOS AUTÓMATAS Y EL MOTIVO DEL ÁRBOL MECÁNICO: BREVE SEMBLANZA CONTEXTUAL}

La palabra autómata proviene del griego av̉ tó $\mu \alpha \tau o \varsigma$, que significa espontáneo. Actualmente este término, cuya primera aparición en literatura no científica se debe a Rabelais (Gargantúa y Pantagruel, I, XXIV), remite a una máquina que imita la figura y los movimientos de un ser animado (DLE s.v. autómata). Un autómata, entonces, es un robot, avant la lettre, cuya historia y genealogía se pierden en la oscuridad de los tiempos; ya que, a pesar de los grandes avances científicos que han inaugurado el nuevo milenio, desconocemos por completo cuándo o por qué fueron inventados estos artefactos. Pese a esta incertidumbre, se sabe que en el viejo Egipto y en la antigua Grecia existían ciertas estatuas móviles que estaban asociadas a las ceremonias sacras y al espectáculo. ${ }^{3}$

Más tarde, la Alejandría helenística fue el escenario perfecto para dar nacimiento a una industria fabulosa y fantástica que comienza con un nombre: Herón, quien se basó en el legado de Arquímides y Filón de Atenas para escribir dos tratados: De Pneumática y De autómata. En ellos, Herón incluye aproximadamente 66 principios eólicos e hidráulicos para la construcción de objetos miméticos móviles, que van desde aves metálicas que cantan y beben en las fuentes, puertas que abren y cierran por sí solas, hasta figuras de hombres con la capacidad de tocar distintos instrumentos musicales e incluso teatros completos de autómatas que materializaban pasajes míticos, como la construcción en miniatura que representaba a Hércules obteniendo las manzanas de las Hespérides (fig. 1). ${ }^{4}$

Por otro lado, la Edad Media contó con sabios que desarrollaron esta técnica, basándose en los estudios de Herón de Alejandría y otros ingenieros helenísticos. Entre ellos se encuentra Alberto Magno, a quien por mucho

\footnotetext{
${ }^{3}$ Acerca de esto, Aracil ha señalado que: "los ejemplos más antiguos que conocemos son egipcios: una estatua de Anubis con la mandíbula móvil para simular que hablaba o la leyenda de las estatuas de Tebas que hablaban y movían los brazos. Uno de los ejemplos más repetidos por los historiadores, desde la Antigüedad, es el de la estatua colosal de Memnon erigida cerca de Tebas que, con los primeros rayos del sol, producía el ruido de las cuerdas de una lira cuando se rompe, según testimonio de Pausanias" (Juego y artificio, 26).

${ }^{4}$ En la actualidad es difícil conseguir una versión impresa de los tratados de Herón, aunque el lector puede acceder a una versión digitalizada de la edición de Bennet Woodcroft en el sitio avalado por la University of Rochester, N. Y: <http://www.history.rochester.edu/steam/ hero/index.html>.
}

Medievalia 49, 2017, pp. 5-19 


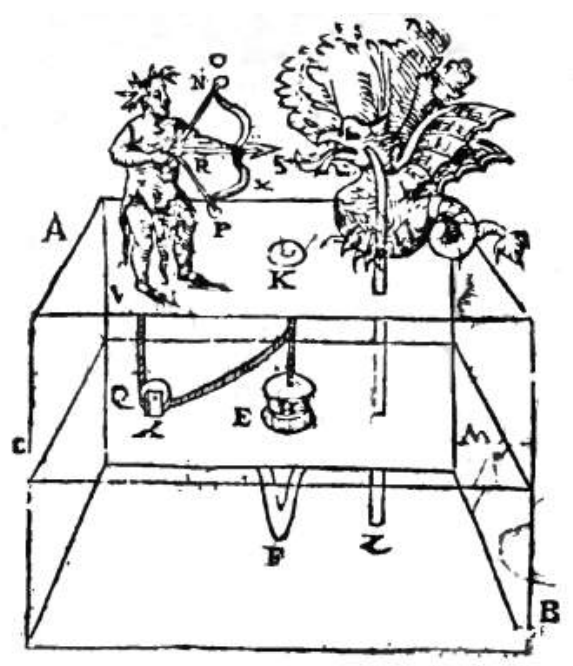

Fig. 1. Reconstrucción del autómata "Hércules y el Dragón", según Giovanni Battista Aleotti, en Gli artificiosi et curiosi moti spiritali di Herrone..., Bolonia, Carlo

Zenero, 1647. Actualmente en Biblioteca Nazionale Centrale di Roma.

tiempo se le atribuyó la fabricación de una cabeza parlante; así como Al-Jazari, científico árabe contemporáneo al siglo áureo islámico (s. XII) e inventor de los primeros relojes mecánicos, como el reloj-elefante, compuesto por representaciones humanas y animales (fig. 2). Durante este mismo periodo, hay que recordar las atribuciones que se le hicieron a Virgilio como un auténtico padre de portentos, entre los cuales se hallaban precisamente un número considerable de autómatas y demás objetos colindantes entre lo mecánico y lo mágico. ${ }^{5}$

En el ámbito de la literatura occidental, no obstante, las primeras menciones a autómatas las encontramos en la Antigüedad Clásica. Así, desde

${ }_{5}^{5}$ La figura de Virgilio en la Edad Media ha sido estudiada por Domenico Comparetti en su texto Vergil in the Middle Ages, donde dedica un capítulo (I, 239-257) a la figura del poeta visto como un auténtico taumaturgo, es decir, aquel que obra maravillas y milagros. Entre esos mirabilia, no sólo se encuentra la capacidad de hablar con los muertos, que nos daría la imagen del "Virgilio niogromante", sino la supuesta fabricación de diversos autómatas. Carlos Alvar, por su parte y basándose en los estudios de Comparetti, también habla de la imagen del poeta latino como obrador de cosas maravillosas. Así, afirma que "los clérigos ingleses y alemanes del siglo XII atribuían al poeta latino los más variados motivos novelescos de origen poco claros. Juan de Salisbury (1115) y Gervasio de Tilbury (s. XIII) son los primeros que aluden a las capacidades mágicas de Virgilio" (“De autómatas", 21). 
Fig. 2. El reloj elefante: del Libro del conocimiento y el ingenio mecánico de Al-Jazari. Manuscrito conservado en The Metropolitan Museum of Art of New York. Cora Timken Burnett Collection of Persian Miniatures and Other Persian Art Objects, Bequest of Cora Timken Burnett ( MS.57.51.23).

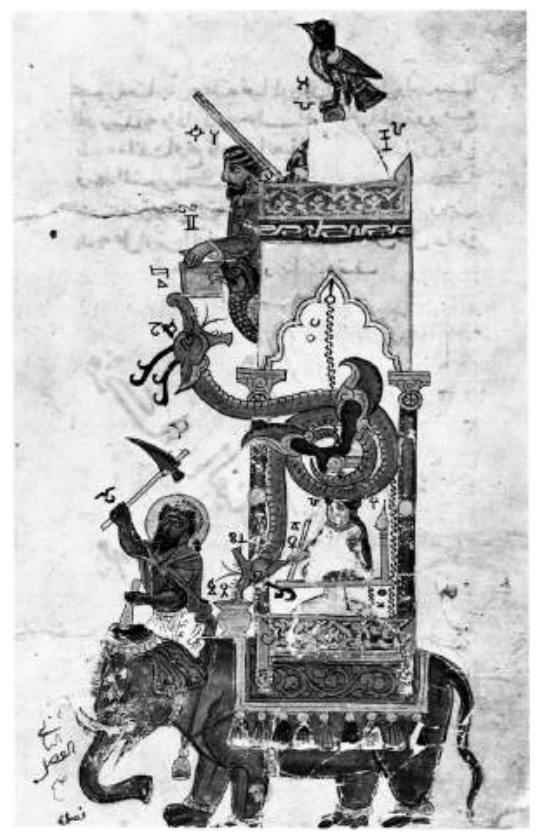

principios del siglo pasado, algunos autores como Douglas Bruce ("Autómatas humanos", 513) consideraron que Talos, el legendario gigante de bronce con quien se encuentra Jasón en Creta (Argonáutica II, IV; Apolodoro, I, 140), puede ser una muestra clara de este tipo de construcciones llevadas al plano mimético literario. Por otro lado y con menos especulación que el ejemplo anterior, en la Ilíada, Homero cuenta que, entre las muchas curiosidades que se hallan en la gruta del Etna, donde Hefestos tiene su fragua, el dios del fuego poseía "unas sirvientas de oro, semejantes a vivientes doncellas. En sus mientes hay juicio, voz y capacidad de movimiento y hay habilidades que conocen pese a los inmortales dioses" (XVIII, vv. 416-420, 489). ${ }^{6}$

La literatura medieval también es rica en la representación de dichos objetos, a los cuales casi siempre se les sitúa en los terrenos del Otro. Entiéndase esto ya sea como el país de las hadas — que a su vez debe codificarse como

${ }^{6}$ Aunado a estos ejemplos y a pesar de que no tratemos con material estrictamente literario, habría que recordar que, por otra parte, Aristóteles ya alude a estos objetos en sus obras. Así, en De Anima (I, 3), el maestro de Alejandro habla de una Venus de madera construida por Dédalo y que tiene la capacidad de movimiento gracias al mercurio; mientras que, en la Politica (I, cap. II, 5), vuelve a hacer mención de estos artefactos hechos por el constructor del mítico laberinto y los llama "estatuas móviles".

Medievalia 49, 2017, pp. 5-19 
la tierra de los muertos-; o bien, precisamente, como parte de la parafernalia, en las descripciones de los palacios orientales; e incluso en las écfrasis o descripciones de sepulcros que tratan, al interior de los textos, de eternizar la fama de un personaje célebre.

Tomando en cuenta lo anterior, en literatura medieval hallamos autómatas en obras como Le pèlegrinage de Charlemagne à Jérusalem, donde se describe el palacio giratorio del rey de Bizancio, Hugon, y los infantes de bronce que, gracias a la energía eólica, impulsan el movimiento del alcázar (vv. 345362). Hallamos autómatas también en Le Roman d'Eneas, donde se describe, por una parte, un concierto de aves metálicas en la sala del trono de la reina Dido (vv. 452-486); o bien el mecanismo autómata que celosamente guarda la sepultura de Camille (vv. 7593-7784). Finalmente, encontramos referen10 cias a autómatas en las diversas narraciones que medievalizaron la vida de Alejandro Magno, entre las cuales un lugar especial lo ocupa la Historia de Proeliis, pues - como ya lo ha señalado Ian Michel ("Automata in the Alexan$d r e ", 275)$ - al parecer el autor del LA se basó en esta obra para incluir el pasaje del árbol en su versión hispánica. En efecto, cualquier lector de la HP que lea también las cuadernas correspondientes al $L A$ se dará cuenta que ambos episodios son similares, pues en la primera de estas obras se lee lo siguiente:

Ingresssus [est Alexander] Palatium Pori et invenit ibi, que incredibilia humanis sensibus viderentur, videlicet quadringentas columpnas aureas cum capitellis aureis preparatas, et inter ipsas columpnas vinea aurea cum foliis aureis dependebat $[\ldots]$ Et in aula ipsius palatii erant statue auree constitute, inter quas erant platanii auree, in quarum ramis avium multa genera consistebant, et avis quelibet secundum naturalem colorem depicta erat. Rostra vero et ungule ex auro purissimo videbantur. Hec aves quocienscumque volebat Porus melodificantes secundum suam naturam per artem musican concinebant (cap. LXXXI, 108-110).

Cabe mencionar que la presencia del árbol autómata no surge en la $H P$ ex nihilo, sino que el rastreo del motivo debe llevarnos, primero, a campos extraliterarios. De esta manera, habría que recordar que objetos como éste eran más o menos comunes en las cortes islámicas del siglo viI. Así Legros menciona que:

Nous savons que le calife Abd-Allâh-al Mâmoûn possédait, vers l'an 827, à Bagdad, un automate représentant un arbre dans les branches duquel se trouvaient des oiseaux animés. Un objet identique est décrit dans la relation faite par un historien arabe de la réception à Bagdad d'un envoyé de Byzance, Constantin 
Porphyrogénète, entre 1060 et 1070. L’ambassadeur fut reçu dans un palais appelé Dàr ash-Shadjara, c'est-à-dire le «Palais de l'Arbre» ("Connaissance, réception et perceptions", 108). ${ }^{7}$

Claramente, este palacio toma su nombre a causa del objeto que ahí figuraba; un objeto muy parecido al que proponen tanto la $H P$ como, siglos después, el $L A$. Más allá de esto, entre líneas, la cita refleja el encuentro con la Otredad; pues, efectivamente, el conocimiento histórico de la presencia de estos objetos en las cortes orientales nos ha llegado gracias a los escritos de embajadores occidentales o cristianos en Oriente, o bien debido a testigos oculares de estas embajadas, como el mencionado Porfirogéneta, que sin duda fue partícipe de esta ostentación de lujo y poder.

Más célebre, conocido y estudiado resulta Liutprando de Cremona quien, en el año de 950, viajó a Bizancio como embajador del rey de Italia, Berengeno II; y de esto dejó noticia en su Relatio de Legatione Constantinopolitana. Un documento en el que describe lo que vio en Constantinopla y, en particular, en el Gran Palacio; y de donde se desprenden numerosos retratos literarios a autómatas, que ya han sido estudiados por Brett ("The Automata", 477); Legros (“Connaissance, réception et perceptions”, 108) y Aracil. ${ }^{8}$ No obstante, de entre esas descripciones, cabe resaltar la siguiente:

\footnotetext{
${ }^{7}$ Este "Palacio del árbol" y su autómata sobrevivieron por lo menos hasta el siglo XIII. Época en la que Abulfeda, historiador y geógrafo árabe, describe también el palacio del árbol en Bagdad de la siguiente manera: "Inter alia rari et stupendi luxus spectacula erat arbor aurea et argéntea in octodecim ramos maiores diducta, per quos ceterosque minores ramulos utriusque formae sedebant aves, areae et argenteae. Arbor haec foliis ex utroque metallo conflatis radiabat; et prout rami sese motitarent machini acti, sic aves certos et destinatos quaeque modulos recinebant Inter alia rari et stupendi luxus spectacula erat arbor aurea et argéntea in octodecim ramos maiores diducta, per quos ceterosque minores ramulos utriusque formae sedebant aves, areae et argenteae" (en Brett, "The Automata", 483). Por otra parte, el segundo personaje al que se refiere Legros es Constantino Porfirogéneta (905-959), "el príncipe nacido en la púrpura”. Llamado así, porque nació en la sala púrpura del Gran Palacio de Constantinopla, lugar donde nacían los herederos al imperio. Fue hijo del emperador León VI el sabio y sobrino de Alejandro III. Constantino Porfirogéneta, como Alfonso X el sabio, es recordado en mayor medida por su proyecto cultural y su empuje hacia las letras. Entre las obras que manda realizar se encuentra un libro llamado De ceremonis o Libro de las ceremonias, en donde describe los diferentes actos políticos y religiosos de la urbe, entre ellos la recepción de embajadores. Es ahí justamente donde se hace mención a los autómatas, cuyos diseños seguramente fueron importados gracias a su viaje a Bagdad, como lo señala la cita.

${ }^{8}$ Brett, por ejemplo, habla del libro De ceremonis, donde se da cuenta de ciertos procesos ceremoniales y diplomáticos que solían practicar los emperadores de Constantinopla para recibir embajadas extranjeras. De este modo, se habla de las ceremonias llevadas a cabo en
}

Medievalia 49, 2017, pp. 5-19 
Aerea sed deaurata quaedam arbor ante Imperatoris oculos stabat, cujus ramos itidem aereae diversi generis deaurateaque volucres replebant, quae secundum spicies suas diversarum avium voces emittebant $[\ldots]$ Cumque in adventu meo rugitum leones emitterent, aves secundum species suas perstreperent, nullo sum terrore, nulla admiratione commutus, quoniam quidem ex his omnibus eos qui noverant fueram percontatus (Relatio ..., en Legros, "Connaissance, réception et perceptions", 109).

Además de que la cita sugiere ya un concierto de máquinas organizado y sistematizado, lo descrito por Liutprando hace pensar que el autómata del Palacio del árbol, en Bagdad, pronto fue imitado en la corte bizantina. Una idea que se sostiene al pensar, por una parte, en el viaje que hizo "El príncipe de la 12 Púrpura” a Bagdad; mientras que, por otra, no hay que olvidar que Constantinopla se codificó durante la Edad Media — por motivos geográficos y comerciales - como un puente entre Oriente y Occidente, por el cual no sólo fluían las mercancías, sino también las ideas, las narraciones y las descripciones. ${ }^{9}$

Como quiera que esto haya sido, la Relatio de Liutprando debió sensibilizar la imaginación de sus lectores y escuchas contemporáneos, ya que la descripción del objeto se convirtió en un motivo que se difundió rápidamente en toda Europa y no tardó en aparecer tanto en las literaturas latinas medievales —éste es el caso de la $\mathrm{HP}$-, como en las letras vernáculas en reciente formación. Los estudiosos del tema (Legros, "Connaissance, réception et perceptions", 105; Brett, "The Automata”, 478) han tomado como ejemplo de estas últimas a l'arbre aux oiseaux que aparece en la primera parte del Yvain ou le Chevalier au lion, de Chrétien de Troyes (ca. 1076); o bien el árbol metálico de La Prise d'Orange (ca. 1120). ${ }^{10}$ Sin embargo, habría que mencionar

el Triclinium y en la cuales participaban, como espectáculo, aves cantoras y leones artificiales rugientes, además de otras bestias móviles. Aracil, por su parte, se centra en las maravillas musicales que tenían, asimismo, fines políticos y de fiesta (Juego y artificio, 276).

${ }^{9}$ Tanto Brett ("The Automata", 482) como Michel ("Automata in the Alexandre", 280) defienden abiertamente la idea de la importación del árbol autómata de Bagdad hacia Bizancio, hecha — según estos estudiosos - durante el imperio de Teófilo (813-842).

${ }^{10}$ Para un estudio sobre el árbol y La Prise... véase A. Labbé, La Prise d'Orange ou l'arbre dans le palais. L'architecture des palais et des jardins dans la chanson de geste. Essai sur le thème du roi en majesté, Paris-Genève,1987, pp. 235-329. Ahora bien, resulta interesante lanzar la hipótesis de que el motivo pudo haber llegado a Occidente a partir de la relación política -muchas veces en tensión-, que tuvieron los normandos con las cortes orientales. Es decir que, dejando a un lado la visión folkorista, las narraciones más antiguas que contienen el motivo son francesas. De ahí pasaría, más o menos en el siglo XIII, a España. 
que el motivo también permea la literatura hispánica medieval, que cuenta con ejemplos como el que aparece en la Embajada de Tamorlan, donde se describe un árbol áureo cargado de piedras preciosas en la tienda de Khano, esposa del emperador tártaro; ${ }^{11}$ o bien, y por antonomasia, la obra que en este trabajo nos ocupa, el Libro de Alexandre, y en cuya manifestación del motivo me centraré a continuación.

\section{El ÁRBOL AUTÓMATA EN EL LA: ESTRUCTURA Y FUNCIONES ECFRÁSTICAS}

Estructuralmente, la descripción del árbol autómata en el $L A$ es un pasaje que abarca once cuadernas del texto (cc. 2131-2142). Asimismo, se constituye como una parte subordinada, en un segundo nivel, a otros pasajes mayores del Libro; pues está incluida, primero, en la enunciación de las maravillas de la India y, dentro de éstas, en la larga descripción del palacio de Poro. Ahora bien, como sucede con los ejercicios ecfrásticos de otros mirabilia en el $L A$, este episodio se divide de manera interna. Así, esta subdivisión y sus respectivas correspondencias con las cuadernas se delega a cinco puntos fundamentales:

1. Introducción (c. 2132)

2. Écfrasis visual (cc. 21333-2135)

3. Écfrasis musical (cc. 2136-2139)

4. Otras maravillas (cc. 2140-2141)

5. Cierre del pasaje (c. 2142)

En la única cuaderna que el autor del LA utiliza como introducción, se lee también cierta información fundamental para entender el episodio. Veamos:

\footnotetext{
${ }^{11}$ El texto dice: "Delante de este dicho platero o mesa estava un árbol de oro, fecho a semejança de robre, que avía el pie tan grueso como podría ser la pierna de un omne, con muchas ramas que salían e ivan a una parte e a otra, con sus fojas como de robre; e sería tan alto como un omne, e pujava sobre el platero que cerca d'él estaba. E la fruta que este dicho árbol avía, eran muchos balaxes e esmeraldas e turquesas e çafires e rubís e aljófar muy grueso, a maravilla, claros y redondos escogidos, y guarnidos en muchas partes por el árbol. Otrosí por el dicho árbol ivan muchas paxarillas de oro, esmaltadas e fechas de muchas colores, e estaban asentadas por el árbol, d'ellas las alas abiertas e d'ellas, asentadas sobre las fojas del árbol, como que se querién caher. Et fazíen semejança que queríen comer de aquella friuta del árbol” (VIII, 14, 299-300).
}

Medievalia 49, 2017, pp. 5-19 
En medio del enclaustro, lugar tan acabado, sediá un rico árbol en medio levantado, nin era mucho gruesso nin era muy delgado, de oro fino era sotilamente obrado (c. 2132).

El verso "d" de esta cuaderna devela que el árbol, en realidad, es producto del dominio orfebre; pues, por una parte, se menciona que está hecho de oro, un rasgo que debe interpretarse como símbolo del poder económico de las cortes de Oriente; mientras que, por otro lado, en el mismo verso hallamos un sintagma adjetivo (sotilmente obrado) que devela la artificialidad y, asimismo, la maestría con la que fue hecho el objeto.

Las tres cuadernas siguientes (cc. 2133-2135) constituyen la descrip14 ción del árbol por medio del recurso de la ennumaratio o fragmentación de sus partes constitutivas que igualmente son también tres. Una cuaderna para cada elemento: aves (c. 2133), instrumentos juglarescos (c. 2134) y cañones de bronce (c. 2135). ${ }^{12}$ Veamos con detalle sólo el primero de esos elementos, es decir las aves, que el autor ubica en las ramas del árbol y describe de la siguiente manera:

Cuantas aves en el çielo han bozes acordadas, que dizen cantos dulçes menudas e granadas, todas en aquel árbol parçién tragitadas, cad' un de su natura, en color devisadas (c. 2133).

En las aves que aparecen en esta cuaderna - mismas que ya se observaban en el pasaje correspondiente de la HP - Michel ("Automata in the Alexandre", 280) ha identificado el influjo que produjeron los autómatas de Herón de Alejandría en la Edad Media; pues, en sus tratados, como lo hemos visto, algunas de las figuras que abundan son, precisamente, pájaros artificiales que, gracias a la energía eólica e hidráulica, poseen movimiento e incluso sonido. No obstante, algo que podríamos añadir al estudio de Michel es resaltar una idea vinculada absolutamente con el ejercicio descriptivo; y es que, en esta cuaderna, el autor del Alexandre hace un juego de representaciones por demás interesante; ya que, en primer lugar, no describe a un ser vivo, sino la representación de un animal. Por tanto, al utilizar el lenguaje como medio comunicativo, el autor hace la representación de una representación y, por

\footnotetext{
${ }^{12}$ Esta división del pasaje puede aunarse a la tesis de Cañas, quien ha señalado que el texto es claramente tripartito y el número tres domina la obra ("Didactismo y composición", 70).
} 
consiguiente, el ejercicio mimético es doble. Ahora bien, la representación propuesta es, como he dicho, de naturaleza absolutamente visual pues, por lo menos el verso "d" obliga al receptor a formarse una imagen mental, dado que las aves se presentan ahí divididas y clasificadas tanto por su natura, como por sus colores.

Casos más o menos similares son las dos cuadernas siguientes (c. 2134, c. 2135), donde el autor del LA alude, primero, a la presciencia de instrumentos musicales "bien atemprados", es decir bien afinados; y, después, cañones de cobre que yacen enterrados a la raíz del árbol. No es, sino a partir del verso "a”, de la cuaderna c. 2136, cuando comienza la enargeia o movimiento en la descripción. ${ }^{13}$ Una presencia vívida que la écfrasis gana a partir de la musicalidad y el ordenamiento sucesivo de los sonidos. Así:

Sollavan con bufetes en aquellos cañones,

luego dizián las aves cada una sus sones,

los gayos, las calandras, los tordes e gaviones,

el ruiseñor que dize las más hermosas canciones (c. 2136).

La musicalidad, como se observa, está dividida y organizada en una especie de orquestación. Esto es, primero suenan los cañones y después cada una de las aves canta aquello que le es propio o natural. Siguiendo esta lógica, cuando el autor menciona que "luego dizián las aves cada una sus sones", y da cuenta de cada una de ellas, obliga indirectamente a que el lector o escucha se haga una imagen mental de todas las especies que allí son representadas (tragitadas), pero también nos obliga a crearnos una "imagen auditiva”, pues alude al tipo de canto que a cada pajarillo acompaña, por lo cual la écfrasis es también musical.

El ejercicio de la orquestación se repite en la siguiente cuaderna, pues ahí el autor da cuenta de la secuencia en que se suscitan la participación de cada uno de esos tres elementos constituyentes, que siguen este esquema: cañones $\rightarrow$ aves $\rightarrow$ instrumentos de cuerda $\rightarrow$ instrumentos de viento. Sucesión tan maravillosa, menciona el autor, que incluso Orfeo sería incapaz de imitar tal prodigio:

${ }^{13}$ Por enargeia entiendo lo señalado por Lunde. Es decir: "the power of language to create a vivid prescence" ("Rhetorical enargeia", 52). Esto es, si bien en una écfrasis los objetos que se describen son pretendidamente estáticos, éstos, por el poder del lenguaje, parece que tuvieran movimiento.

Medievalia 49, 2017, pp. 5-19 
Bolvién los enstrumentos a buelta con las aves, modulavan çierto las cuerdas e los claves, alçando e premiando fazién cantos suaves, tales que por Orfeo de formar serían graves (c. 2138).

La écfrasis musical se intensifica en la c. 2139, pues aquí el autor menciona tipos de tonos y géneros musicales, caracterizando cada uno de ellos. Así las debailadas se identifican con lo dulce; el semitón con lo melancólico, las doblas lo mismo que la anterior; y todo ello, en conjunto, se equipara a la música que puede escucharse en una procesión, por lo que tendríamos ya un guiño dirigido hacia lo magnánimo, hacia lo impresionante y hacia la espiritualidad. Veamos:

Allí era la música cantada por razón, las dulçes debailadas, el plorant semitón, las doblas que refieren cuitas al coraçón, bien podién tirar preçio a una prosiçión (c. 2139).

Lo mismo que menciona Trannoy con respecto al palacio del rey Hugon, que aparece en Le pèlegrinage de Charlemagne, puede aplicarse aquí con relación al árbol autómata en el palacio de Poro. Es decir, "L’harmonie qui règne donc à l'interieur du palais [... ] est suggerée par la douceur de la musique des androïdes et par la régularité du mouvement qui le meut ("De la technique a la magie", 236). En este sentido, el árbol y su concierto son parte de una orquestación (visual) mayor: esto es, el retrato que se hace de un pretendido locus amoenus — aunque ciertamente artificial_-; pero también estos elementos son parte de la evocación de un microcosmos, donde el árbol mismo - como símbolo que une lo ctónico y lo celeste- es el axis mundi que rige este espacio. ${ }^{14}$ En suma, cuando se piensa en la descripción de este objeto en el LA tendríamos que afirmar, como lo ha hecho Legros con respecto a la descripción de otros árboles autómatas, lo siguiente:

Les automates assument dans la littérature du XIIème siècle une fonction narrative de signes et de symboles: symbole d'un pouvoir autocratique, symbole de la tout-puissance sur le monde et sur ses créatures, signes d'un autorité quasi

${ }^{14}$ Trannoy también delega la misma función al autómata en la descripción del palacio del rey de Bizancio, en Le pèlegrinage... : "Le palais est presenté comme un microcosme organicé autor de l'axe qu'est le pilier central [... microcosme évoque par les peintures murales" ("De la technique a la magie”, 240). En el caso del texto hispánico, el microcosmos está dado por la presencia de esas aves artificiales y esos diminutos instrumentos musicales. 
magique, [... et aussi il y a] des symboles plus anciens liés à la représentation de tout souveraineté. Ainsi l'arbre est par excellence, le symbole d'un pouvoir cosmocrator, enraciné dans la terre et tourné vers les choses célestes; le chant des oiseaux renvoie à l'harmonie du monde celle que doit préserver tout souverain (“Connaissance, réception et perceptions", 125).

Ante esta cita, sólo cabría hacer la siguiente pregunta: ¿intratextualmente, ese soberano destinado a guardar la harmonía del mundo es Alejandro? Digamos que, para el tiempo y el mundo inmediato que propone la obra, sí; ya que al hacer suyo el palacio de Poro, Alejandro cierra un capítulo de una historia caótica: la subyugación de su pueblo. Con esto, se vuelve también el nuevo señor del alcázar, el nuevo señor de ese mundo maravilloso al que le impone sus propias reglas, las reglas del macedonio.

Mas no adelantemos conclusiones y prestemos atención a otro aspecto del pasaje que es igualmente interesante, pero de índole extratextual, el cual se halla en las siguientes dos cuadernas, que se enfocan en aspectos meramente de admiración. Y es que, por un lado, se alude nuevamente a tipos de tonos y se alaba la técnica con la que está hecha la obra (c. 2141); mientras que, por otra parte, en la cuaderna previa, la exposición de lo mecánico muda pronto al campo de la maravilla, pues se afirma lo siguiente:

Non es en tod' el mundo omne tan sabidor que decir vos pudiesse quál era la dulçor, mientre omne biviesse en aquella sabor, non abrié set nin fambre, nin ira, nin dolor (c. 2140).

En efecto, la música del árbol autómata se convierte en una especie de panacea y alimento sagrado que cubre, por lo menos, dos de las necesidades vitales del hombre; la sed y el hambre. De la misma forma, el objeto tiene la capacidad de detener la ira y mitigar cualquier dolor. Un hecho que ciertamente resulta tópico pues, en muchos casos, los palacios ubicados en Oriente, o bien los objetos que éstos guardan, tienen el poder de curar malestares físicos, evitar la vejez, derrotar la melancolía o bien, como en este caso, cubrir necesidades fundamentales. ${ }^{15}$ Con todo esto el autor apela a una de las fun-

${ }^{15}$ Este es el caso del palacio construido por Casidiós, supuesto padre del Preste Juan, quien para su heredero manda construir un alcázar, cuya virtud es tal que: "en él nadie sufrirá hambre ni enfermedad y ninguno de los que entren en su interior podrá morir en el transcurso de ese mismo día. Y cualquiera, con un hambre atroz o una enfermedad mortal, saldrá

Medievalia 49, 2017, pp. 5-19 
ciones más constantes de lo maravilloso, la función compensatoria que extratextualmente, según Le Goff ("Le merveilleux", 461), mitiga las carencias de la vida cotidiana y promete que, en algún lugar, siempre se encontrará un mundo mejor al que se vive.

Siguiendo esta lógica, es indudable que la descripción del autómata en el palacio del rey Poro dio al hombre hispánico del medioevo una imagen —idealizada o no- de los reinos y cortes de Oriente que, extratextualmente, fueron codificados como auténticos espacios de poder, lujo y maravillas. Espacios que, por sinécdoque, aluden al Otro - al mundo oriental, al mundo del islam, al mundo de lo no cristiano-, un Otro que, en determinado momento, puede ser peligroso, ya que si el hombre oriental de esta época es hábil en la manufactura de objetos que simplemente se ocupan para el beneplácito 18 de los monarcas, ¿qué no podría hacer en el campo de guerra? Frente a esta lectura, estamos entonces ante la literatura como una mímesis del ejercicio político, pues a través de lo descrito en una de las écfrasis más bellas de la literatura medieval en nuestro idioma, sin duda, se va dibujando la ontología de la Otredad.

\section{BiBLIOGRAFÍA}

Alvar, Carlos, "De autómatas y otras maravillas", en Nicasio Salvador Miguel, Santiago López-Ríos y Esther Borrego Gutiérrez (eds.), Fantasía y literatura en la Edad Media y los Siglos de Oro, Pamplona-Madrid-Frankfurt, Universidad de Navarra: Iberoamericana-Vervuert, 2004, 29-54.

ArACIL, Alfredo, Juego y artificio: autómatas y otras ficciones en la cultura del Renacimiento a la Ilustración, Madrid: Cátedra, 2000.

BRETr, G., “The Automata in the Byzantine Throne of Solomon”, Speculum, 29, 1954, 477-487.

BRuce, Douglas, "Autómatas humanos en la tradición clásica y el romance medieval", Filología Moderna, 10.4, 1913, 511-526.

Cañas Murillo, Jesús, "Didactismo y composición en el Libro de Alexandre", Anuario de Estudios Filológicos, 18, 1995, 65-80.

Clavijo, Ruy De, Embajada a Tamorlán, ed. de Francisco López Estrada, Madrid: Castalia, 1999 (Clásicos Castalia, 242).

tan saciado de él como si hubiese comido cien viandas o tan sano como si no hubiera tenido enfermedad alguna en su vida" (La carta del Preste Juan, 102). 
Comparetri, Domenico, Vergil in the Middle Ages, introd. de Jan M. Ziolkowski, Princeton, NJ: Princeton University Press, 1997.

Genette, Gerard, Palimpsestes: La littérature au second degré, Paris: Seuil, 1982. Homero, Ilíada, ed. de Emilio Crespo Gúemes, Madrid: Gredos, 2008 (Biblioteca Clásica, 150).

La carta del Preste Juan, ed. de Javier Martín Lalanda, Madrid: Siruela, 2003.

Le Goff, Jacques, “Le merveilleux dans l'Occident médiéval”, en su libro Une Autre Moyen Âge. Paris: Gallimard, 2000, 453-476.

Legros, Huguette, "Connaissance, réception et perceptions des automates orientaux au xIIe siècle”, en Gerard Chandes (ed.), Le merveilleux et la magie dans la littérature: actes du colloque de Caen, 31 août-2 septembre 1999, Amsterdam: Rodopi, 1999, 103-136.

Le pèlegrinage de Charlemagne/ La peregrinación de Carlomagno, ed. de Isabel de Riquer, Barcelona: El Festín de Esopo, 1984.

Le Roman D'Eneas, édition, traduction, présentation et notes d'Aimé Petit, Paris: Livre de Poche, 2003.

Libro de Alexandre, ed. de Juan Casas Rigall, Madrid: Castalia, 2010.

LUNDE, INGUNN, "Rhetorical enargeia linguistic pragmatics. On speech-reporting strategies in East Slavic medieval hagiography and homiletics", Journal of Historical Pragmatics, 5:1, 2004, 49-80.

Michel, Ian, "Automata in the Alexandre: pneumatic birds in Porus's Palace", en Ian Macpherson y Ralph Penny (eds.), The medieval mind. Hispanic studies in honour of Alan Deyermond, London: Tamesis, 2000, 275-288.

Prosa Alexanderroman, Historia de Proeliis, ed. de Alfons Hilka, Halle (Netherlands): Max Niemeyer Verlag, 1920.

Spitzer, Leo, “The 'Ode on a Grecian Urn', or Content vs Metagrammar”, Comparative Literature, 7, 3, Summer 1955, 203-225.

Teón, Hermógenes, Aftonio, Ejercicios de retórica, trad. de Ma Dolores Reche Martínez. Madrid: Gredos, 1991 (Biblioteca Clásica Gredos 158).

Trannoy, Patricia, "De la technique a la magie: enjeux des automates dans Le voyage de Charlemagne à Jéruslamen et à Constantinople", en Gerard Chandes (ed.), Le merveilleux et la magie dans la littérature: actes du colloque de Caen, 31 août-2 septembre 1989, Amsterdam: Rodopi, 1992, 227-252.

Medievalia 49, 2017, pp. 5-19 
